\title{
Expression of the Secretory Leukoprotease Inhibitor Gene in Epithelial Cells
}

\author{
Tatsuya Abe," Nobuyuki Kobayashi," Kunihiko Yoshimura," Bruce C. Trapnell," Haimee Kim,* Richard C. Hubbard," \\ Michael T. Brewer, ${ }^{*}$ Robert C. Thompson, ${ }^{\star}$ and Ronald G. Crystal ${ }^{\star}$ \\ *Pulmonary Branch, National Heart, Lung, and Blood Institute, National Institutes of Health, \\ Bethesda, Maryland 20892, and ${ }^{\ddagger}$ Synergen, Boulder, Colorado 80301
}

\begin{abstract}
The secretory leukoprotease inhibitor (SLPI) gene codes for a 12-kD protein that within the lung protects the airway epithelium from neutrophil elastase. Screening of 228 alleles in 114 individuals for sequence differences by RNase protection of genomic DNA revealed no detectable polymorphisms in SLPI gene exons II-IV.SLPI gene expression in the lung was demonstrated by identifying SLPI mRNA transcripts in bronchial epithelial cells freshly isolated from normals. Cell lines derived from mucosal surfaces (HS-24 bronchial squamous cell carcinoma, HeLa cervical carcinoma) actively transcribe the SLPI gene and contain SLPI mRNA transcripts, while lung fibroblasts demonstrate no evidence of SLPI gene expression. SLPI mRNA transcripts appear to be relatively stable, with mRNA levels only mildly affected by inhibition of RNA synthesis. Chromatin DNA of HS-24 cells demonstrates two DNase I hypersensitivity sites within the $5^{\prime}$ flanking region of exon I of the SLPI gene, whereas fibroblast chromatin has no DNase I accessible sites in the same region. Further analysis of the $5^{\prime}$ flanking region demonstrated two contiguous transcription start sites, CAAT and TATA boxes, and several potential regions of known DNA binding proteins. Overall, the SLPI gene appears to be a relatively nonpolymorphic, stable gene that is constitutively expressed at specific tissue sites, but has the potential to be modulated at both the transcriptional and posttranscriptional levels. (J. Clin. Invest. 1991. 87:2207-2215.) Key words: polymorphism • transcription • mRNA transcript stability $\bullet$ DNase I hypersensitivity site $\bullet 5^{\prime}$ flanking region
\end{abstract}

\section{Introduction}

Secretory leukoprotease inhibitor (SLPI) ${ }^{1}$, a 12-kD nonglycosylated serine antiprotease, is found in fluids lining mucosal surfaces, including those of the respiratory tract (1-5). SLPI is capable of inhibiting a variety of proteases, but its major function is to inhibit neutrophil elastase (NE) and cathepsin $G(2$, 4-6). The association rate constant for NE and SLPI is $10^{7} \mathrm{M}^{-1}$ $\mathrm{s}^{-1}(6)$. The SLPI protein is comprised of a single chain with eight intramolecular disulfide bonds $(2,7)$. Crystallographic

Address reprint requests to Ronald G. Crystal, M.D., Pulmonary Branch, Building 10, Room 6D03, National Institutes of Health, Bethesda, MD 20892.

Received for publication 15 November 1990 and in revised form 30 January 1991

1. Abbreviations used in this paper: $\alpha 1 \mathrm{AT}, \alpha 1$-antitrypsin; CF, cystic fibrosis; NE, neutrophil elastase; PCR, polymerase chain reaction; SLPI, secretory leukoprotease inhibitor.

The Journal of Clinical Investigation, Inc.

Volume 87, June 1991, 2207-2215 evaluation demonstrates a "boomerang"-like molecule of two domains, with the active inhibitory site for NE in the $\mathrm{COOH}$ terminal domain (7).

SLPI is thought to provide one of the major anti-NE protections of the epithelium of the large airways (4-8). Unlike $\alpha 1$ antitrypsin ( $\alpha 1 \mathrm{AT})$ which is synthesized primarily in the liver, and to a lesser extent in alveolar macrophages, and provides anti-NE protection to the lung by diffusing across the respiratory tissues mostly from plasma (5), SLPI is believed to be produced locally in the lung by airway epithelial cells. Consistent with this concept, SLPI levels in upper airway epithelial lining fluid of normal individuals are 6-12 $\mu \mathrm{M}$, whereas SLPI levels in plasma are 4-7 nM $(4,9,10)$, and immunohistologic studies have localized SLPI to bronchial serous, goblet, and Clara cells $(1,3)$.

Although the SLPI gene has been characterized as including four exons, spanning $2.6 \mathrm{~kb}$ (11), nothing is known about the relative polymorphic nature of the gene, whether or not the gene is actually expressed in the human lung, or how the expression of the gene is modulated. To begin to address these questions, the present study was directed toward $(a)$ screening a population of individuals for mutations in SLPI gene coding exons, (b) evaluating human bronchial epithelium for direct evidence of expression of the SLPI gene, $(c)$ evaluating a bronchial cell line for evidence of modulation of SLPI gene expression at the transcriptional and/or mRNA levels, and $(d)$ characterizing the $5^{\prime}$ flanking region of the SLPI gene.

\section{Methods}

Screening genomic DNA for mutations in coding exons of the SLPI gene. Screening of the SLPI gene for polymorphisms was carried out using RNase protection evaluation of exons in genomic DNA. The strategy for screening was to determine if polymorphisms could be detected in the major coding exons (II-IV) of the SLPI gene in genomic DNA of individuals with known polymorphisms in the major coding exons (II-V) of the $\alpha 1 \mathrm{AT}$ gene (a gene coding for a protein that serves the same category of function in the lung as does SLPI). The normal SLPI gene includes four exons $(11,12)$. The mature protein is comprised of 107 amino acids; exon I codes for the $5^{\prime}$ untranslated region, the 25 residue signal peptide and residues $1-3$ of the mature protein; exon II, residues 4-56; exon III, residues 57-106; and exon IV, residue 107 and the $3^{\prime}$ untranslated region. The active inhibitory site is centered about residue 72 in exon III $(7,11-13)$.

The source of the genomic DNA included individuals with various polymorphisms in $\alpha 1 \mathrm{AT}$ coding exons. The $\alpha 1 \mathrm{AT}$ alleles were identified from serum $\alpha 1 \mathrm{AT}$ levels, using isoelectric focusing analysis of serum, and genomic analysis as previously described $(14,15)$. The DNA samples included $(a)$ for evaluation of exons II and III of the SLPI gene, 104 individuals with the following $\alpha 1$ AT alleles, M1 $(n=81)$, M2 (36), $M 3$ (5), $M_{\text {heerten }}(1), Z$ (70), $S$ (7), $P_{\text {saint albans }}(1), W_{\text {bethedada }}$ (1), Null $_{\text {granite falls }}(1), \operatorname{Null}_{\text {procida }}(3), \operatorname{Null}_{\text {bellingham }}(1), \operatorname{Null}_{\text {mattawa }}(1)$; and (b) for evaluation of exon IV of the SLPI gene, 55 individuals with the $\alpha 1$ AT alleles, M1 (42), M2 (11), M3 (2), $M_{\text {heerlen }}(1), Z$ (46), S (4), $P_{\text {saint albans }}(1), W_{\text {bethesda }}(1)$, Null $_{\text {bellingham }}(1)$, Null $_{\text {matrawa }}(1)$. In addition, 
genomic DNA samples were evaluated from 10 nonsmoking individuals who had developed chronic obstructive lung disease before age 30 despite lack of evidence of $\alpha 1 \mathrm{AT}$ deficiency or cystic fibrosis (CF) (i.e., normal $\alpha 1 \mathrm{AT}$ phenotypes and normal sweat chloride tests). The $\alpha 1 \mathrm{AT}$ alleles among these individuals, included M1 (14), M2 (3), and S (3). This group (referred to as "early COPD" in the text) was included based on the hypothesis that, in the context that the major role of SLPI in the lung appears to be protection of the airway epithelium, this group of non- $\alpha 1 \mathrm{AT}$ deficiency, non-CF individuals may represent a skewed group of individuals with SLPI coding exon mutations.

To evaluate exons II-IV of the SLPI gene for polymorphisms, genomic DNA was obtained from blood leukocytes, the exons amplified individually using the polymerase chain reaction (PCR), and the resulting amplified DNA screened using RNase protection with sense and antisense probes complementary to the known SLPI exon sequences $(11,12)$. (See reference 16 for a complete description of the method and a discussion of the sensitivity of this approach to screen for various types of mutations.) For exon II, the sense primer (5'-ATCACTCCCAGCCTTCCTCT- $3^{\prime}$ ) and antisense primer (5'-CACCTGGCTCTCCTAGAACT-3') produced a 700-bp fragment; for exon III, the sense primer (5'-CGGTAGCCTCACTCTCACCC-3') and antisense primer (5'-CCCCCTGCCCATATGCCTGG-3') produced a 260 -bp fragment; and for exon IV, the sense primer (5'-AGCAGGGGACGAGGGCACAC-3') and antisense primer (5'-AACGAATCACAGAAGCAGGA3 ) produced a 780-bp fragment (see Fig. $1 A$ for locations of the primers). For controls, a 260-bp DNA fragment spanning exon III and its flanking introns was made by PCR as described above using the entire SLPI gene $(11,12)$ in pUC8 (pPB132) as a template. Two independent single base mutations were also introduced by $P C R$, including $\mathrm{G} \rightarrow \mathrm{C} 50 \mathrm{bp}$ from the $5^{\prime}$ end of exon III in the codon for residue $\mathrm{Met}^{98}$ of the mature SLPI protein and C $\rightarrow$ G 110 bp from the $5^{\prime}$ end of exon III in the codon for residue Cys ${ }^{118}$. All PCR reactions utilized $100 \mathrm{ng}$ genomic DNA or $1 \mathrm{ng}$ cDNA per $100 \mu \mathrm{l}$ reaction mixture and PCR was carried out for 25 cycles under standard conditions (17). The RNA probes used for screening were prepared by in vitro transcription from the complete SLPI cDNA in a linearized pGEM vector (pPB135) utilizing the T7 (for the antisense probe) and SP6 (for the sense probe) RNA polymerases (both from Promega Biotec, Madison, WI) with [ ${ }^{32}$ P]UTP $(800 \mathrm{Ci} / \mathrm{mmol}$; Amersham Corp., Arlington, IL). The antisense probe (pPB228, 678 nucleotides [nt]) included all four coding exons and flanking sequences of the vector, as did the sense probe (pPB229, $604 \mathrm{nt})$.

To screen the PCR-amplified exons of genomic DNA, $1 \mu$ l of DNA from each reaction was hybridized with the ${ }^{32} \mathrm{P}$-labeled antisense and
A

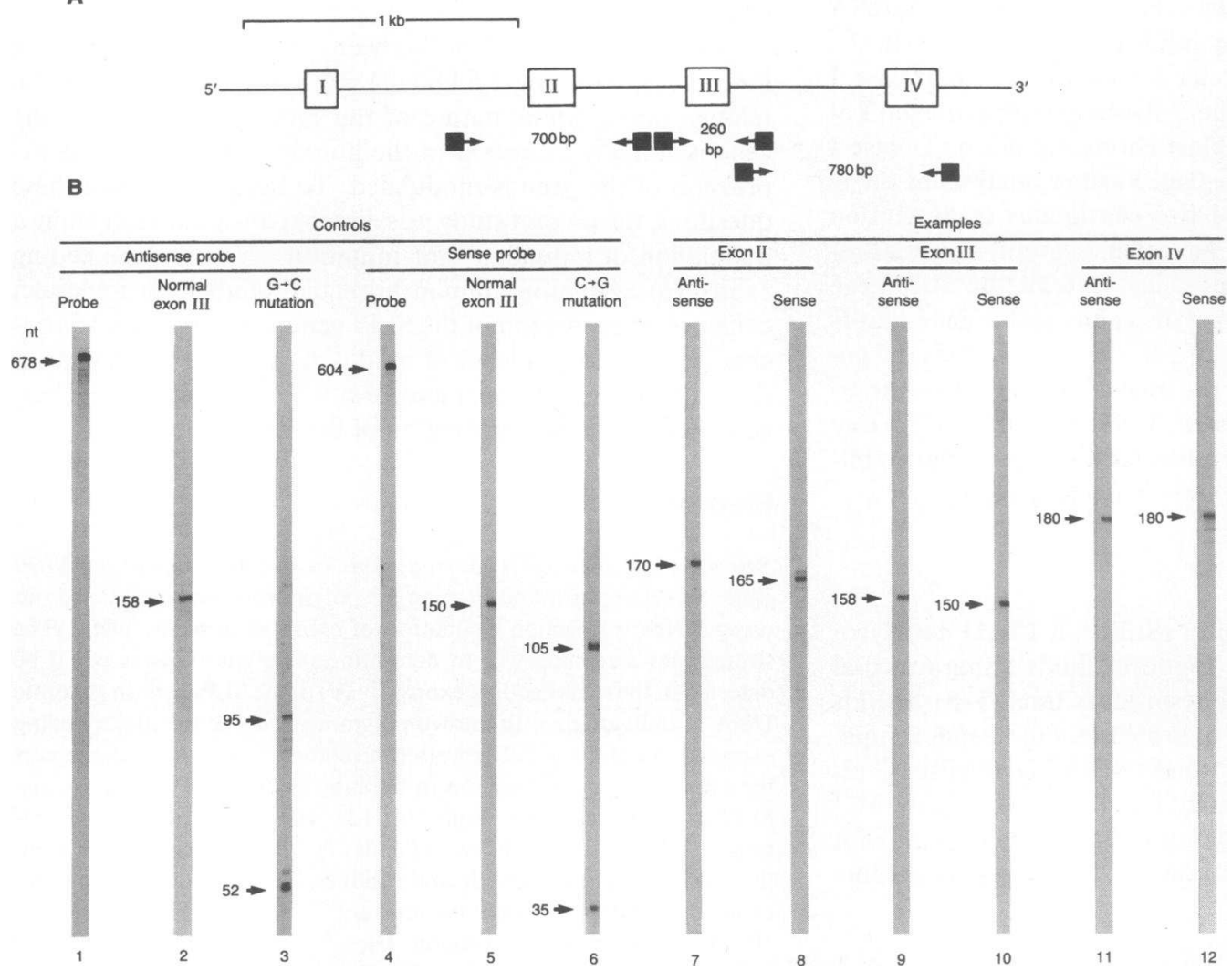

Figure 1. Screening of the major SLPI coding exons in genomic DNA for the presence of DNA polymorphisms. (A) Schematic representation of the SLPI gene. Indicated are the locations of oligonucleotide primers used to amplify segments of the SLPI gene containing exons II, III, and IV $(700,260$, and 780 bp, respectively). (B) Examples of screening analysis. To evaluate individuals for mutations within the SLPI gene, amplified genomic DNA containing SLPI exons II, III, or IV was hybridized to ${ }^{32} \mathrm{P}$-labeled antisense or sense cRNA probes, followed by RNase digestion, gel electrophoresis, and autoradiography. (Lanes 1-6) Controls; (lanes 7-12) examples of analysis for each exon. (Lane 1) cRNA antisense probe without hybridization or RNase digestion. (Lane 2) Antisense probe after hybridization to a cloned DNA fragment representing the normal exon III sequence;

the protected fragment is $158 \mathrm{bp}$, representing the intact exon III sequence. (Lane 3) Same as lane 2, but hybridized to a DNA fragment representing the normal exon III sequence but with the change of an artificial mutation (G $\rightarrow C$ at nucleotide residue 50 of exon III); note that the $G \rightarrow C$ mutation permits cleavage, resulting in two fragments of the probe. (Lane 4) cRNA sense probe without hybridization or RNase digestion. (Lane 5) Sense probe after hybridization to a cloned DNA fragment representing the normal exon III sequence. (Lane 6) Same as lane 5 , but hybridized to the same cloned, artificially mutated exon III (C $\rightarrow G$ at nucleotide residue 110 of exon III); note the two fragments resulting from the $C \rightarrow G$ mutation. (Lane 7) PCR-amplified exon II from genomic DNA from a normal individual after RNase protection with an antisense probe. (Lane 8) Identical to lane 7, but with the sense probe. (Lane 9) Same genomic DNA, but with PCR-amplified exon III evaluated with an antisense probe. (Lane 10) As in lane 9, but with the sense probe. (Lane 11) Same genomic DNA, but with PCR-amplified exon IV evaluated with an antisense probe. (Lane 12) As in lane 11, but with the sense probe. In each lane, the size of observed protected probe fragments is shown in nucleotides (nt). Differences from the expected size of the protected probes are due to the slight difference in structural conformation between the antisense and sense RNA probes in relation to migration of the DNA molecular size markers. 
sense probes and the resulting DNA-RNA hybrids were subjected to RNase treatment. The amounts of RNase A (37-74 $\mu \mathrm{g} / \mathrm{ml}$; Sigma Chemical Co., St. Louis, MO) and RNase $T_{1}(0-1.8 \mu \mathrm{g} / \mathrm{ml}$; United States Biochemical Corp., Cleveland, $\mathrm{OH}$ ) were adjusted for each combination of probe and exon to minimize the background. After RNase digestion, the protected fragments of the probe were evaluated by gel electrophoresis of $6 \%$ polyacrylamide $/ 8 \mathrm{M}$ urea followed by autoradiography. The expected lengths were: antisense probe alone, $678 \mathrm{nt}$, sense probe alone, $604 \mathrm{nt}$; normal exon II DNA evaluated with antisense probe, $159 \mathrm{nt}$, with sense probe, $159 \mathrm{nt} ; \mathrm{G} \rightarrow \mathrm{C}$ mutated exon III with antisense probe, 50 and $100 \mathrm{nt} ; \mathrm{C} \rightarrow \mathrm{G}$ mutated exon III with sense probe, 110 and $40 \mathrm{nt}$; normal exon III DNA with antisense probe, 150 $\mathrm{nt}$; with sense probe, $150 \mathrm{nt}$; normal exon IV DNA with antisense probe, $179 \mathrm{nt}$, and with sense probe, $179 \mathrm{nt}$.

Evaluation of normal airway epithelial cells for SLPI mRNA tran scripts. To demonstrate expression of the SLPI gene in human bronchial epithelial cells, the epithelium was obtained from normal volunteers by brushing the large bronchi with a cytology brush through a fiberoptic bronchoscope (18). Purity of bronchial epithelial cells was $>95 \%$ as proved by histological staining. The epithelial cells were shaken off the brush into RPMI 1640 medium at $4^{\circ}$, centrifuged $(1,500$ $\mathrm{rpm}, 5 \mathrm{~min}$ ), and total cellular RNA was extracted using acid guanidinium isothiocyanate-phenol-chloroform method (19). First-strand cDNA synthesis was carried out using Moloney Murine Leukemia Virus reverse transcriptase (Gibco/BRL, Gaithersburg, MD) and oligo$d T$ primers (Collaborative Research, Inc., Bedford, MA). SLPI cDNA was amplified by PCR using sense (5'-ACTCCTGCCTTCACCATGAA-3') and antisense (5'-CATTCGATCAACTGGCACTT- $3^{\prime}$ ) primers as described above. $\gamma$-Actin transcripts (as a control) were evaluated with $\gamma$-actin-specific primers (5'-ATGAAGATCAAGATCATCATCGCACCC-3') and (5'-CACCAAGCCACCGACTTGTCTTCC$\left.3^{\prime}\right)$. The PCR reaction products were Southern transferred to nylon membranes (Nytran; Schleicher \& Schuell, Keene, NH), hybridized with a ${ }^{32}$ P-labeled 219-bp SLPI cDNA probe (pPB223) encompassing exons III and IV (see Fig. 2), or $\gamma$-actin cDNA probe (pHF $\gamma \mathrm{A}-1)(20)$, and evaluated by autoradiography. The full-length SLPI cDNA (pPB135) was used as a template for a positive control and cDNA converted from the HepG2 hepatoma cell line (HB 8065; American Type Culture Collection [ATCC], Rockville, MD) RNA as a negative control for the SLPI mRNA detection.

Expression of the SLPI gene in cultured cell lines. To further characterize expression of the SLPI gene, three cell lines were evaluated: HS24 (a human lung squamous cell carcinoma cell line known to contain SLPI mRNA transcripts and produce SLPI [21], kindly provided by W. Ebert, Thoraxklinikum, Heidelberg-Rohrbach, Germany), HeLa (human cervical carcinoma cell line, ATCC CCL2), and HFL1 (diploid human fetal lung fibroblast, ATCC CCL 153). HS-24 was cultured in RPMI 1640 with $25 \mathrm{mM}$ Hepes, pH 7.4 (Gibco/BRL), $2 \mathrm{mM}$ glutamine and $100 \mu \mathrm{g} / \mathrm{ml}$ gentamicin (Gibco/BRL), 10\% FCS (Biofluids, Rockville, MD). HeLa and HFLl were cultured in DMEM (Whittaker Bioproducts, Walkersville, MD), 10\% FCS, 2 mM glutamine, $100 \mathrm{U} /$ $\mathrm{ml}$ penicillin, and $100 \mu \mathrm{g} / \mathrm{ml}$ streptomycin (all from Biofluids).

Northern analysis of total cellular RNA ( $5 \mu \mathrm{g}$ for each cell line) was carried out as previously described (22) with the ${ }^{32} \mathrm{P}$-labeled SLPI cDNA (pPB131) and, as a control, $\beta$-actin cDNA (pHF $\beta A-1)$ (20) probes. RNase protection analysis was carried out to quantify the SLPI mRNA transcripts in HS-24 and HeLa cell lines, and to insure that HFL1 cells did not contain SLPI mRNA transcripts. The evaluation was similar to that used to screen the SLPI coding exons for polymorphisms. Briefly, a ${ }^{32} \mathrm{P}$-labeled antisense cRNA probe (pPB230) was used to evaluate the RNA samples from those cell lines, and unlabeled sense SLPI cRNA was synthesized by the SP6 transcription of pPB 135 as a standard (see Fig. $3 \mathrm{~B}$ ). All assays contained $10 \mu \mathrm{g}$ RNA. The amounts of RNases included $37 \mu \mathrm{g} / \mathrm{ml}$ RNase $A$ and $1.8 \mu \mathrm{g} / \mathrm{ml}$ RNase $T_{1}$. Hybridization, gel electrophoresis, and autoradiography were carried out as described above. The amounts of SLPI mRNA transcripts were quantified based on a standard curve made with unlabeled synthetic sense SLPI cRNA and normalized according to the size of this
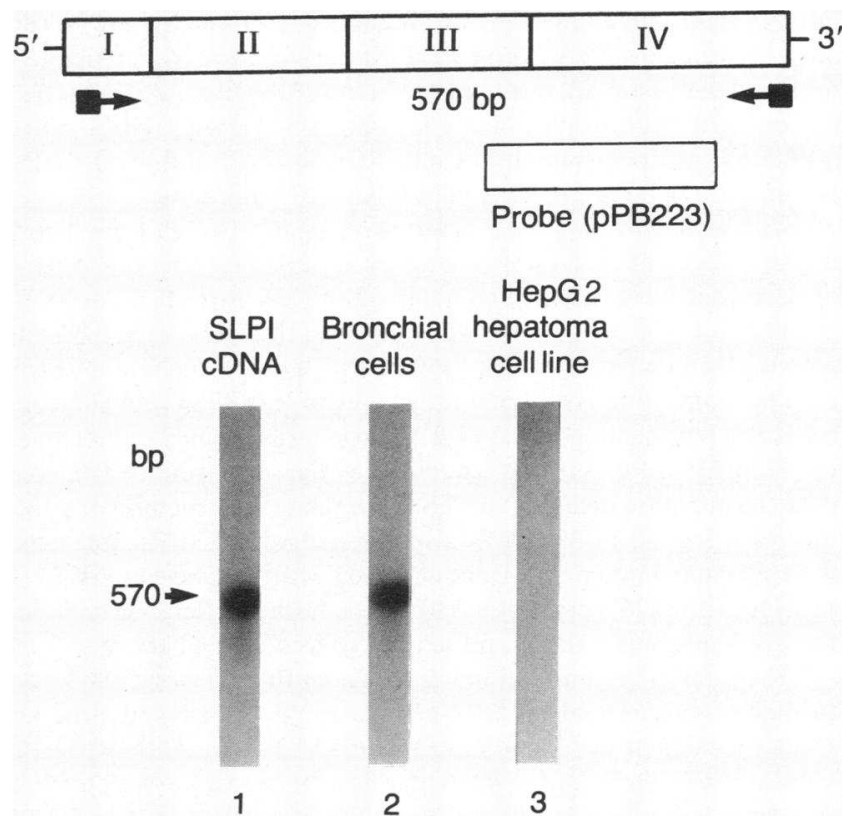

Figure 2. Expression of the SLPI mRNA transcripts in freshly isolated normal human bronchial epithelial cells. (Top) Map of the SLPI cDNA corresponding to the full-length mRNA. Indicated are the locations of 5'-sense and 3'-antisense oligonucleotide primers used to amplify SLPI mRNA transcripts and the nested probe (pPB223) used to detect amplified SLPI transcripts. (Bottom) Evaluation for SLPI transcripts. (Lane 1) Cloned SLPI cDNA (as a positive control). (Lane 2) RNA from bronchial epithelial cells. (Lane 3) RNA from HepG2 hepatoma cells (as a negative control). The expected 570-bp specific amplification product is indicated by the arrow.

standard RNA and true cellular SLPI mRNA transcripts and direct counting of radioactivity corresponding to each band on the gels using a liquid scintillation counter.

To assess the relative transcription rate of the SLPI gene in each cell line, nuclei were isolated from cultured cells using 0.5\% NP-40 for HS-24 and HeLa cells, and $0.2 \%$ NP-40 for HFL1 cells as previously described $(23,24)$. The isolated nuclei were incubated $\left(30 \mathrm{~min}, 37^{\circ}\right)$ with ribonucleotides including $\left.{ }^{32} \mathrm{P}\right] \mathrm{UTP}$, and the nascent RNA transcripts were purified with acid guanidinium isothiocyanate-phenolchloroform as described above. The unincorporated nucleotides were eliminated by Sephadex G-50 column chromatography. Heat denatured DNA targets ( $5 \mu \mathrm{g}$ for each) were immobilized onto nitrocellulose membranes (BA85, Schleicher \& Schuell) by using a Schleicher \& Schuell dot blot apparatus, and cross-linked to the membranes by UV light. The plasmids used were pPB132 for the SLPI gene, pUC19 as a negative control and pHF $\beta \mathrm{A}-1$ for $\beta$-actin cDNA as a positive control. Hybridization of ${ }^{32} \mathrm{P}$-labeled RNA to immobilized DNA, wash, and RNase treatment for the membranes were performed as described by Nevins (24).

To assess the effect of inhibitor of transcription on SLPI mRNA transcript levels, cultured HS-24 and HeLa cells were exposed to actinomycin D (5 $\mu \mathrm{g} / \mathrm{ml}$, Sigma Chemical Co.). The cells were cultured for $0-24 \mathrm{~h}$ in the presence or absence of actinomycin D, total cellular RNA was then extracted, and SLPI mRNA levels were quantified by RNase protection analysis as described above, and parallel evaluation of $\beta$-actin mRNA transcript levels was carried out by Northern analysis with the $\mathrm{pHF} \beta \mathrm{A}-1$ probe.

DNase I hypersensitivity site mapping. The 5 ' flanking region of the SLPI gene was evaluated for DNase I hypersensitivity sites in nuclei isolated from HS-24 and HFL1 cells (25). To accomplish this, the nuclei were isolated as described above, and then exposed to DNase I ( 20 $\mathrm{ng} / \mu \mathrm{g}$ DNA; Boehringer Mannheim Biochemicals, Inc., Indianapolis, 
IN) for $0,0.5,1$, or $2 \mathrm{~min}$. The chromatin DNA was then extracted and purified. $10 \mu \mathrm{g}$ of DNA from each DNase I digestion was completely restricted with Bam $\mathrm{HI}$, electrophoresed on $1 \%$ agarose, and subjected to Southern hybridization analysis using a ${ }^{32} \mathrm{P}$-labeled DNA probe (pPB224) encompassing almost all of the intron I and exon II (Pst I-Bam HI fragment, Fig. 6), and evaluated by autoradiography.

Sequence analysis of the 5' flanking region of the SLPI gene. The 5' flanking region of exon I was isolated from pPB233, a Charon 30 clone of a genomic DNA segment containing the SLPI gene (11). The DNA purified from the phage clone was subcloned into pUC19 by digesting with Pst I, and screened with a ${ }^{32}$ P-labeled 1.0-kb fragment of the SLPI gene encompassing exon I and most of exon II (pPB234). A subclone (pPB225) representing $\sim 1.2 \mathrm{~kb} 5^{\prime}$ to exon I was isolated, resubcloned in $\mathrm{M} 13 \mathrm{mp} 19$ (pPB235), and sequenced by the single-stranded dideoxy chain termination method (26). To characterize the structure of further upstream region, pPB233 was also digested with Eco RI, fragments were subcloned into pUC13, and screened with ${ }^{32} \mathrm{P}$-labeled pPB225. A subclone (pPB226) spanning $1.3 \mathrm{~kb}$ of the further $5^{\prime}$ flanking region of the SLPI gene was isolated and sequenced as described above.

The transcription initiation site for the SLPI gene was identified by primer extension analysis (27), using a $5^{\prime}{ }^{32} \mathrm{P}$-end-labeled antisense primer located at the $3^{\prime}$ end of exon I (5'-ACTTTCCAGAGCCTTCCACAGCCC- $\left.3^{\prime}\right)$. Poly(A) ${ }^{+}$RNA purified by oligo- $d T$-cellulose chromatography from total cellular RNA of HS-24 and HeLa cells was used as the template. Identification of the length of the extended primer was accomplished by parallel primer extension with a sequencing reaction of the single-stranded DNA template (pPB235) using the same primer.

Computer analysis, performed with DNASIS (Hitachi America, Brisbane, CA) and FASTA (28) was used to evaluate the $5^{\prime}$ flanking sequence for homology with ,other gene promoter sequences in the DNA database GenBank and for homology with putative regulatory sequences. Included among the latter were consensus sequences for TATA and CAAT boxes, and the trans-acting regulatory protein binding sites for AP-1 (29), AP-2 (30), Spl (31), CAAT-enhancer binding protein (C/EBP) (32), glucocorticoid receptor (GR) (33), cAMP response element binding protein (CREB) (34), and Octamer-1 (OCT-1) and Octamer-2 (OCT-2) (35), using the criteria of Mitchell and Tjian (36) and allowing for up to one mismatch from the consensus sequences.

\section{Results}

Screening for mutations in SLPI coding exons. As has been demonstrated for the coding exons of the $\alpha 1$ AT gene (16), RNase protection provides a rapid approach to screening SLPI coding exons for mutations (Fig. 1). Examples of this approach for the SLPI gene include base substitutions placed in exon III (lanes 2, 3, 5, 6). However, despite the sensitivity and accuracy of this method, no base substitutions were identified in the SLPI genome in exon II (208 alleles evaluated), exon III (208 alleles) or exon IV (110 alleles) (Fig. 1, lanes 7-12; Table I). This apparent stability of the SLPI coding exons was even more striking in the context that the genomic DNA evaluated came from individuals with a broad diversity of polymorphisms in the coding exons of the $\alpha 1 \mathrm{AT}$ gene, polymorphisms easily detectable with the same methodology (16). Further, evaluation of 10 individuals with "early COPD" with no evidence of $\alpha 1 \mathrm{AT}$ deficiency or CF also showed no polymorphisms detectable in the SLPI coding exons II-IV (data not shown).

Expression of the SLPI gene in the normal human respiratory epithelium. On the basis of the presence of SLPI in human respiratory epithelial lining fluid (4), and the immunolocalization of the SLPI protein to the bronchial mucus secreting cells $(1,3)$, it has been assumed that the human bronchial epithelium is capable of synthesizing SLPI. Using a cytology brush to directly sample these cells in normals, and using appropriate PCR primers and a SLPI-specific probe, it was possible to directly demonstrate the presence of SLPI mRNA transcripts in these cells (Fig. 2). In this regard, whereas RNA from bronchial epithelial cells demonstrated SLPI transcripts, the control hepatoma cell line did not (compare lanes 2 and 3), although $\gamma$-actin mRNA transcripts were present in both cell types (not shown).

SLPI gene expression in cultured cells. Whereas cell lines derived from mucosal surfaces such as the bronchi and cervix contain SLPI mRNA transcripts, fibroblasts do not (Fig. 3).
A

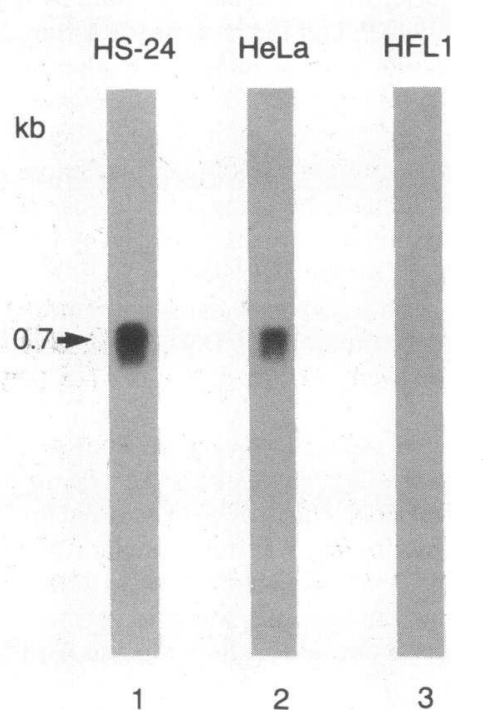

B
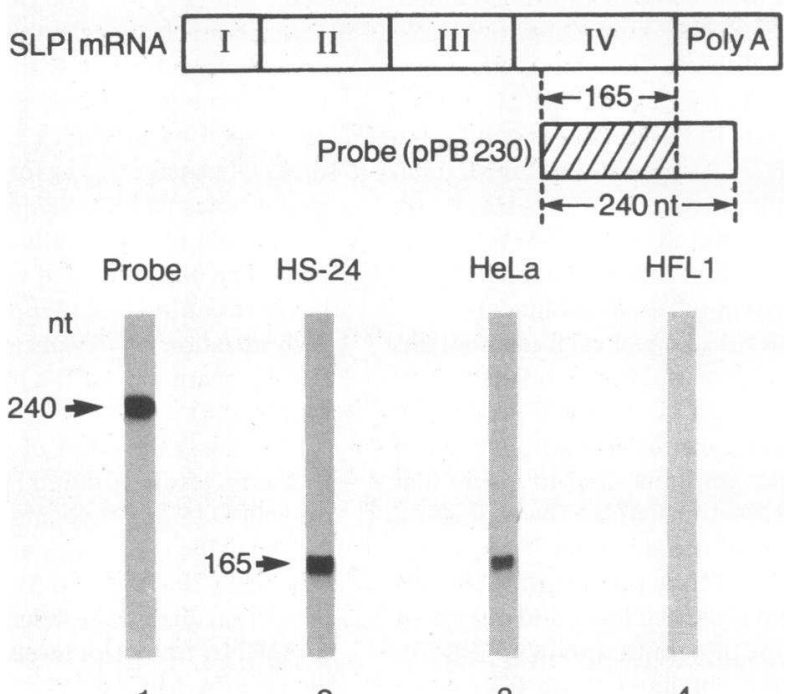

1

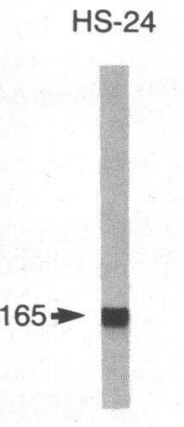

2

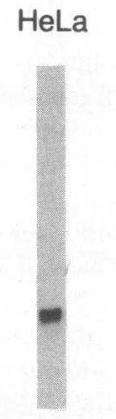

3

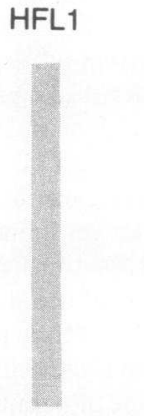

4

Figure 3. Expression of the SLPI gene at the mRNA level in human cell lines. Shown is data from HS-24 human bronchial squamous cell carcinoma cells, HeLa cervical carcinoma cells, and, as a control, HFL1 human diploid fetal lung fibroblasts. $(A)$ Northern analysis. (Lane 1) HS24 cells, demonstrating the 0.7 kb SLPI mRNA transcripts. (Lane 2) HeLa cells, also shown with SLPI transcripts but less amount compared to HS-24. (Lane 3) HFL1 cells; no SLPI mRNA is evident. ( $B$ ) RNase protection analysis. ${ }^{32} \mathrm{P}$-labeled synthetic, antisense SLPI cRNA probe (pPB230) was hybridized with total RNA $(10 \mu \mathrm{g})$, exposed to RNase to degrade unhybridized probe, and analysed by gel electrophoresis and autoradiography. The cRNA probe was $\mathbf{2 4 0}$

nt in length and corresponds to the $3^{\prime} 165$ bases of exon IV with the remainder plasmid vector sequences. (Lane 1 ) Probe without hybridization or RNase digestion. (Lane 2) HS-24 RNA. (Lane 3) HeLa RNA. (Lane 4) HFL1 RNA. 
Table I. RNase Protection Screening of Genomic DNA of Individuals with Various al-Antitrypsin Alleles for Polymorphisms in Coding Exons of the Secretory Leukoprotease Inhibitor Gene

\begin{tabular}{|c|c|c|c|}
\hline \multirow{2}{*}{$\begin{array}{l}\text { SLPI } \\
\text { exons }\end{array}$} & \multicolumn{2}{|c|}{$\begin{array}{l}\alpha 1 \mathrm{AT} \text { alleles of genomic } \\
\text { DNA samples evaluated }\end{array}$} & \multirow{2}{*}{$\begin{array}{l}\text { Number of polymorphism } \\
\text { found in SLPI exons }\end{array}$} \\
\hline & Allele & $n$ & \\
\hline \multirow[t]{9}{*}{ II } & $\mathrm{M}^{*}{ }^{*}$ & 81 & 0 \\
\hline & M2 ${ }^{\circ}$ & 36 & 0 \\
\hline & M3 & 5 & 0 \\
\hline & $\mathbf{M}_{\text {heerlen }}$ & 1 & 0 \\
\hline & Z & 70 & 0 \\
\hline & $\mathbf{S}$ & 7 & 0 \\
\hline & $P_{\text {saint albans }}$ & 1 & 0 \\
\hline & $\mathbf{W}_{\text {bethesda }}$ & 1 & 0 \\
\hline & $\mathrm{Null}^{\ddagger}$ & 6 & 0 \\
\hline \multirow[t]{9}{*}{ III } & $\mathbf{M} 1^{*}$ & 81 & 0 \\
\hline & M2 & 36 & 0 \\
\hline & M3 & 5 & 0 \\
\hline & $\mathbf{M}_{\text {heerlen }}$ & 1 & 0 \\
\hline & Z & 70 & 0 \\
\hline & $\mathbf{S}$ & 7 & 0 \\
\hline & $P_{\text {saint albans }}$ & 1 & 0 \\
\hline & $\mathbf{W}_{\text {bethesda }}$ & 1 & 0 \\
\hline & Null $^{\ddagger}$ & 6 & 0 \\
\hline \multirow[t]{9}{*}{ IV } & $M 1^{*}$ & 42 & 0 \\
\hline & M2 & 11 & 0 \\
\hline & M3 & 2 & 0 \\
\hline & $\mathbf{M}_{\text {heerien }}$ & 1 & 0 \\
\hline & z & 46 & 0 \\
\hline & $\mathbf{S}$ & 4 & 0 \\
\hline & $P_{\text {saint albans }}$ & 1 & 0 \\
\hline & $\mathbf{W}_{\text {bethesda }}$ & 1 & 0 \\
\hline & Null $^{\S}$ & 2 & 0 \\
\hline
\end{tabular}

Individual exons were amplified by the PCR and hybridized with a ${ }^{32} \mathrm{P}$-labeled antisense or sense RNA probe encompassing all coding exons of the SLPI gene; the presence or absence of DNA-RNA sequence differences were evaluated by treatment with RNase A and RNase $T_{1}$, electrophoresis on polyacrylamide gel and autoradiography (see Fig. 1 and Methods). " $\mathrm{M} 1$ " includes $\mathrm{M} 1$ ( $\left.\mathrm{Val}^{213}\right)$ and $\mathrm{M} 1$ $\left(\mathrm{Ala}^{213}\right)(14,15)$. $¥$ "Null” includes Null $\mathrm{granite}_{\text {falls, Null }}$ procida, Null $_{\text {bellingham, }}$ and Null mattawa $_{\text {(see Methods). "Null" includes }}$ Null $_{\text {bellingham }}$ and Null mattawa $_{\text {(see Methods). }}$

This was true for both Northern analysis, where the SLPI transcripts were seen at $0.7 \mathrm{~kb}(A)$, and RNase protection analysis where SLPI mRNA transcripts represented $42.5 \pm 3.3 \mathrm{pg} / \mu \mathrm{g}$ total cellular RNA in HS-24 cells $(n=11)$ and $21.1 \pm 0.7 \mathrm{pg} / \mu \mathrm{g}$ for HeLa $(n=12)(B)$ (all data are presented as mean \pm standard error of the mean and all statistical comparisons were made using the two-tailed Student's $t$ test). Despite the increased sensitivity of the RNase protection, no SLPI transcripts were observed in the fibroblasts ( $B$, lane 4$)$. However, the control $\beta$-actin mRNA transcripts were equally seen in all cell lines (not shown).

Transcription of the SLPI gene. Isolated nuclei from HS-24 and HeLa, but not HFL1 cells, demonstrated active transcrip- tion of the SLPI gene (Fig. 4). In contrast, all three cell lines were actively transcribing the $\beta$-actin gene. However, whereas HS-24 and HeLa cells actively transcribe the SLPI gene, transcription is likely low; relative transcription rate of the SLPI gene to the $\beta$-actin gene is $15 \%$ in HS-24, and $16 \%$ in HeLa, respectively. In this regard, transcription could barely be detectable with a full-length SLPI cDNA (not shown) and it was necessary to use a genomic DNA target to have a signal that was easily observed. The positive signal with the genomic DNA was not secondary to non-SLPI gene repetitive sequences (e.g., in an intron), as no transcription signal was observed in nuclei from fibroblasts. Further, no signal was observed when Eco RI digested pPB132 (the SLPI genomic clone used as a target for the transcription run-on analysis) was hybridized with ${ }^{32} \mathrm{P}$-labeled genomic DNA from HeLa cells. Thus, transcription of the SLPI gene appears to be limited to the epithelial cells such as HS-24 and HeLa cells which are derived from mucosal surface epithelium.

Stability of SLPI mRNA transcripts. Evaluation of the effect of inhibition of RNA synthesis on SLPI mRNA levels in cultured mucosal cell lines suggested that SLPI transcripts are relatively stable, although the effects were different in HS-24 and HeLa cells (Fig. 5). Over a period of $24 \mathrm{~h}$, SLPI transcript levels remained level in untreated HS- 24 cells, but in the presence of actinomycin D, SLPI mRNA levels increased significantly, reaching a level fourfold above the resting level at $24 \mathrm{~h}$ $(A ; P<0.01$ actinomycin D-treated cells vs. HS-24 alone at 24 h). With HeLa, the SLPI transcript levels in untreated cells did not change, but with actinomycin D, SLPI mRNA levels fell, but slowly, suggesting a half-life of $11.5 \mathrm{~h}(B ; P<0.05$ actinomycin D-treated cells vs. HeLa alone at $24 \mathrm{~h}$ ). In contrast to the diverse changes in SLPI mRNA levels in HS-24 and HeLa in the presence of actinomycin $\mathrm{D}, \beta$-actin mRNA levels declined in a similar fashion in both cell lines (not shown).

DNase I hypersensitivity sites in the $5^{\prime}$ flanking region of the SLPI gene. Consistent with the knowledge that cells derived from mucosal surfaces actively transcribe the SLPI gene

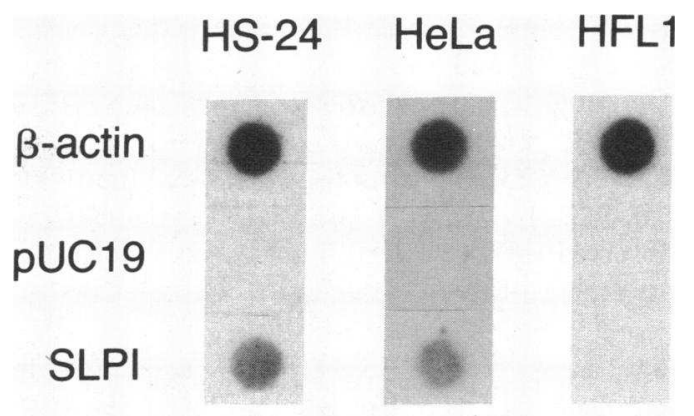

Figure 4. Transcription of the SLPI gene. A nuclear transcription run-on analysis was used to demonstrate active transcription of the SLPI gene in epithelial cells. Isolated nuclei from HS-24, HeLa, or HFLl cells were incubated with $\left[{ }^{32} \mathrm{P}\right] U T \mathrm{P}$ to label nascent RNA. Total nuclear RNA was purified and evaluated by hybridization to an excess amount $(5 \mu \mathrm{g})$ of a filter-bound SLPI genomic DNA target (3.8 $\mathrm{kb}$ including exons I-IV and flanking regions). For comparison, a 2.0-kb $\beta$-actin cDNA in pHF $\beta$ A-1 (as a positive control) and 2.7-kb plasmid vector pUC19 DNA (as a negative control) were evaluated in parallel. In the example shown, the amount of labeled RNA added to each filter was $2.54 \times 10^{6} \mathrm{dpm}$ (HS-24), $5.44 \times 10^{6} \mathrm{dpm}$ (HeLa), and $2.12 \times 10^{6} \mathrm{dpm}$ (HFL1). 


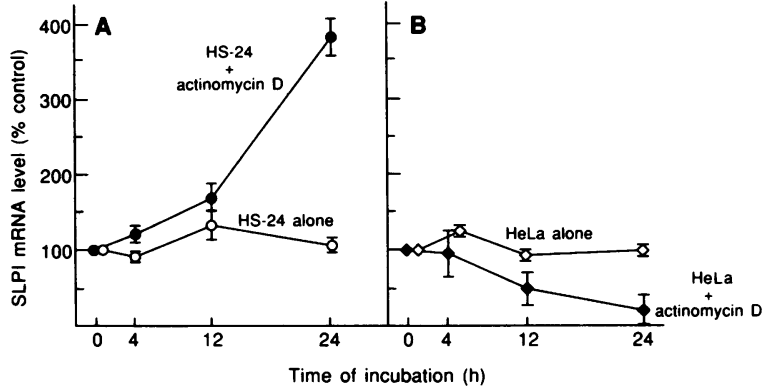

Figure 5. Influence of inhibition of RNA synthesis in the SLPI mRNA transcript levels in epithelial cell lines. $(A)$ SLPI mRNA transcript levels in HS-24 cells. (B) SLPI mRNA transcript levels in HeLa cells. HS-24 or HeLa cells were incubated in the absence or presence of actinomycin D $(5 \mu \mathrm{g} / \mathrm{ml})$ for up to $24 \mathrm{~h}$, total RNA was extracted and the amount of SLPI mRNA transcripts (picograms per microgram RNA) was quantified by RNase protection. Data shown are based on three individual experiments and all values are expressed as a percentage of control values at time zero.

whereas fibroblasts do not, chromatin DNA from HS-24 cells, but not from HFL1 cells, demonstrated hypersensitivity to DNase I in the $5^{\prime}$ flanking region of exon I of the SLPI gene (Fig. 6). In this regard, two hypersensitivity sites were observed in HS-24 cells, 1.7 and $1.2 \mathrm{~kb}$, respectively, $5^{\prime}$ to the Bam HI site in exon II, corresponding to $\sim 0.7$ and $0.2 \mathrm{~kb} 5^{\prime}$ to exon I.

Characterization of the $5^{\prime}$ flanking region of exon 1 . Sequence analysis of $1.4 \mathrm{~kb} \mathrm{5}$ to exon I demonstrated characteristics typical of a gene with cell-specific expression with the potential for regulation (Fig. $7 A$ ). Primer extension analysis in both HS-24 and HeLa showed microheterogeneity in the transcription start site, with two sites observed at contiguous bases 21 and 22 bp $5^{\prime}$ to the translation start codon (HS-24, Fig. 7 B; HeLa, not shown). We defined the most $5^{\prime}$ site as the major transcription start site because the $3^{\prime}$ site may represent the premature fall-off of the reverse transcriptase due to the possible methylation of this residue. Within $27 \mathrm{bp}$ of the major transcription start was a TATA box and at 88 bp a CAAT box. A region with $75 \%$ homology to the Alu repeat sequence was observed between -1307 and $-999(37,38)$. Sites were identified with the potential to bind the transcription factors AP-1 $(-1352,-812,-575$, and -470$)$, AP-2 $(-1264,-284$, and $-219)$, and C/EBP $(-623)$. No consensus sites were found for Sp1, GR, CREB, OCT-1, or OCT-2. The two DNase I hypersensitivity sites observed in HS-24 chromatin correspond to the regions approximately -800 to -550 , and -350 to -200 , respectively.

A homology search using FASTA among sequences in GenBank revealed no regions of strong homology in the SLPI $5^{\prime}$ flanking sequence with other gene promoter sequences, including the promoter of the $\alpha 1 \mathrm{AT}$ gene. Interestingly, direct comparison of SLPI gene and CF gene promoter sequences revealed four separate areas of homology (SLPI -931 to -916, $81 \%$; SLPI -831 to $-821,82 \%$; SLPI -443 to $-430,79 \%$; SLPI -375 to $-357,80 \%)(39)$.

\section{Discussion}

The secretory leukoprotease inhibitor gene codes for a small $(12 \mathrm{kD})$ naturally occurring human protein capable of func-
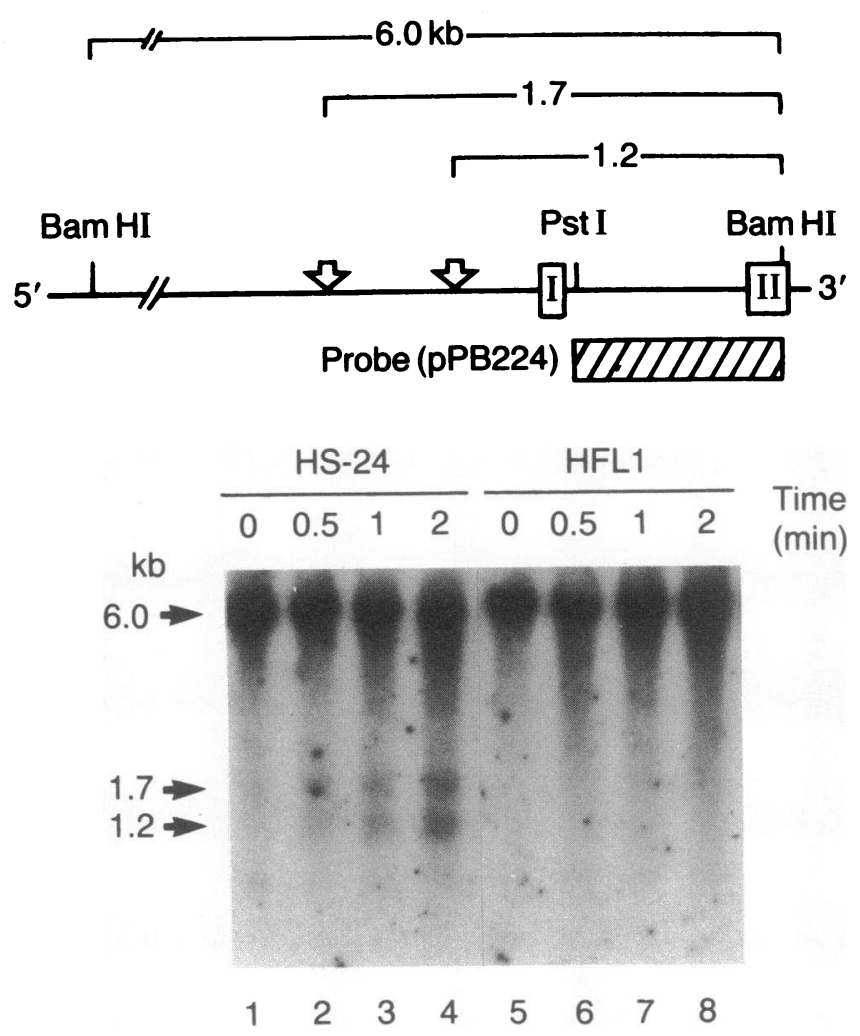

Figure 6. Evaluation of chromatin DNA for the presence of DNase I hypersensitivity sites in the $5^{\prime}$ flanking region of exon I of the SLPI gene. (Top) A partial map of the SLPI gene and 5 ' flanking region showing the 6.0-kb Bam HI restriction fragment used for evaluation of DNase I hypersensitivity sites. The ${ }^{32}$ P-labeled probe (pPB224) encompassed a Pst I-Bam HI fragment as shown. The arrows indicate regions of DNase I hypersensitivity within the $5^{\prime}$ flanking sequence of the SLPI gene (see below). (Bottom) Comparison of DNA from HS-24 and HFL1 cells for DNase I hypersensitivity sites 5 ' to the SLPI gene. Nuclei isolated from HS-24 or HFLl cells were treated with DNase I for 0-2 min, the DNA was then extracted, digested with Bam $\mathrm{HI}$, and evaluated by Southern analysis using the probe pPB224. (Lanes 1-4) HS-24 cell nuclei treated for $0,0.5,1$, and $2 \mathrm{~min}$, respectively. Note the appearance of 1.7 - and $1.2-\mathrm{kb}$ bands indicating DNase I hypersensitivity sites. (Lanes 5-8) HFL 1 cell nuclei treated for $0,0.5,1$, and $2 \mathrm{~min}$, respectively. No DNase I hypersensitivity sites are apparent.

tioning in vivo to inhibit the destructive enzyme, neutrophil elastase $(5,6)$. Studies of biologic fluids and immunohistologic evaluation of tissues suggests that the SLPI gene is expressed in a tissue-specific manner at mucosal surfaces such as those of the lung, cervix, parotid duct, and seminal vesicles $(1,3,6,12$, 40 ). In the lung, where SLPI is thought to play a role in protecting the epithelium of the upper airways against NE, the SLPI can be found in epithelial lining fluid and in the cytoplasm of goblet, serous, and Clara epithelial cells $(1,3,4,8,41)$. Although SLPI levels in the lung are far less than $\alpha 1$ AT levels, SLPI and $\alpha 1 \mathrm{AT}$ are equally effective in vitro as inhibitors of $\mathrm{NE}$, i.e., the dominance of $\alpha 1 \mathrm{AT}$ as the major inhibitor of $\mathrm{NE}$ in mucosal tissues like the lung is because there is far more functional $\alpha 1 \mathrm{AT}$ present than SLPI (5).

In accordance with this concept of tissue-specific expression of the SLPI gene, the present study demonstrates that cell 
A
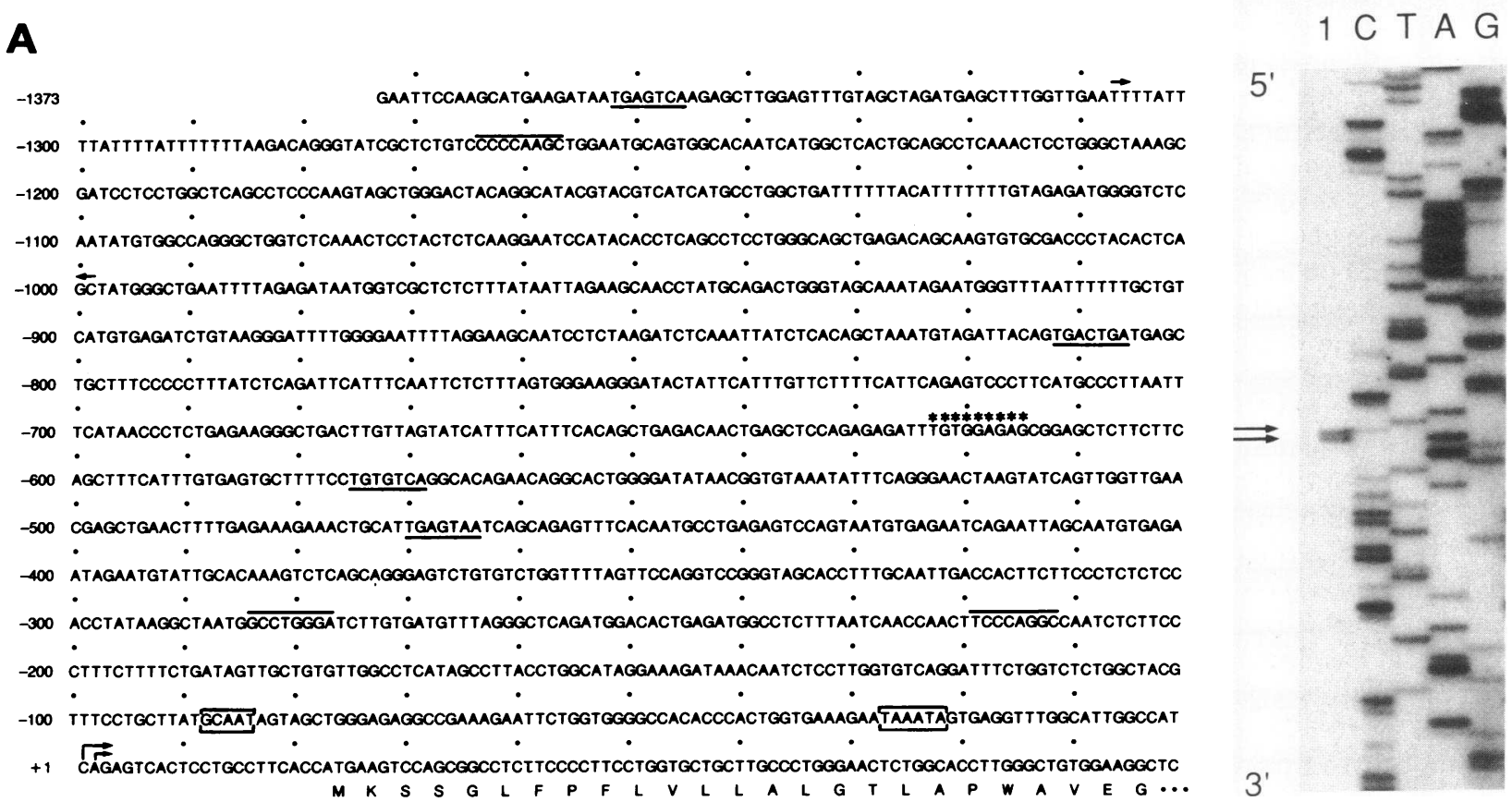

Figure 7. Structural organization of the $5^{\prime}$ flanking region of the SLPI gene. (A) Sequence of the $5^{\prime}$ flanking region of the SLPI gene. A 1.4-kb fragment containing exon I and the 5 ' flanking region of the SLPI gene was sequenced using the dideoxy chain termination method. Transcription start sites are marked by arrows. Numbers are relative to the most $5^{\prime}$ transcription start site (indicated by the longer arrow) as defined in $B$. CAAT and TATA boxes are located at positions -88 and -27 , respectively. Translation of the SLPI protein begins at position +23 , with the first 25 amino acid residues indicated by the single letter code. An Alu repeat sequence is located between positions -1307 and -999 (horizontal arrows). There are potential binding sites for AP-1 (underlined) at positions -1352, $-812,-575$, and -470; AP-2 (overlined) at positions $-1264,-284$, and -219 ; and C/EBP (asterisks) at position -623 . The DNase I hypersensitivity sites (see Fig. 6) map to approximate positions -800 to -550 and -350 to -200 . (B) Determination of the transcription start sites. Shown is the primer extension analysis of poly(A) ${ }^{+} \mathrm{RNA}$ purified from HS-24 cells using the antisense primer located at the end of SLPI gene exon I. (Lane 1) Reaction products using HS-24 poly(A) ${ }^{+}$ RNA. (Lanes $C, T, A$, and $G$ ) Sequence ladders used as the size marker. Two contiguous transcription start sites are indicated by arrows.

lines derived from mucosal surfaces actively transcribe the SLPI gene and contain SLPI mRNA transcripts. Further, whereas chromatin from a lung mucosal cell line demonstrates unprotected DNase I hypersensitivity sites in the $5^{\prime}$ flanking region of the SLPI gene, positions corresponding to these sites are protected from DNase I in cells such as fibroblasts. Although it remains possible that additional hypersensitivity sites may reside upstream or downstream of this region evaluated, these observations imply that the SLPI gene is actively transcribed in mucosal cells, but not in fibroblasts.

The mechanisms controlling SLPI gene expression in vivo are unknown. By directly assessing bronchial epithelial cells obtained by brushing the airway epithelium of normal individuals, we were able to demonstrate that the SLPI gene is expressed in the human airway epithelium at the mRNA level. However, as the number of cells obtained by this approach is limited, and because there are no "normal" culture equivalents of serous, goblet, or Clara cells (the cells that immunohistologic studies suggest express the SLPI gene), it is not possible to make definitive statements about normal regulatory processes. However, based on our in vitro analyses of tumor-derived cell lines from lung and cervix, it is reasonable to conclude that: $(a)$ a major mechanism of regulation of SLPI gene expression occurs at the transcriptional level, and transcriptional regulation likely forms the basis of its tissue-specific expression; $(b)$ posttranscriptional control is also likely, because HS- 24 cells contain more SLPI mRNA transcripts than HeLa cells in spite of almost the same transcription rate of the gene in the two cell types; and $(c)$ SLPI mRNA transcripts appear to be quite stable. Although it is difficult to estimate the half-life of SLPI mRNA transcripts in HS-24 cells because of the increase in the SLPI mRNA levels during incubation with actinomycin $D$, it is likely that the half-life of SLPI mRNA in those cells is much longer than $12 \mathrm{~h}$, because the half-life of SLPI mRNA transcripts in HeLa cells is $11.5 \mathrm{~h}$. The fact that actinomycin D caused an increase in SLPI mRNA levels in HS-24 cells seems unusual, but that phenomenon is probably due to the relatively stable mRNA transcripts of the SLPI gene compared to other mRNA or rRNA particularly in HS-24 cells as discussed above. These observations are specific for SLPI mRNA because $\beta$-actin mRNA transcript levels decline in similar fashion in both HS-24 and HeLa cells, but consistent with the fact that the $3^{\prime}$ untranslated region of SLPI mRNA shows no AUUUA sequence, a destabilizing element for mRNA transcripts $(42,43)$.

Interestingly, analysis of the sequence of SLPI $5^{\prime}$ flanking region demonstrates several regions of close homology with the promoter of the CF gene, a gene also expressed on mucosal surfaces. However, unlike the CF promoter which has charac- 
teristics of a "housekeeping gene" $(39,44)$, the SLPI gene has all of the characteristics of a typical tissue-specific regulated gene $(36,45)$. In this regard, whereas the CF gene $5^{\prime}$ flanking region has no TATA box, but has multiple transcription start sites, a high $\mathrm{G}+\mathrm{C}$ content, and several potential Sp1 binding sites (39), the SLPI gene $5^{\prime}$ flanking region has a TATA box, only one transcription start site (albeit with some microheterogeneity), no high $\mathrm{G}+\mathrm{C}$ content, and no potential binding sites for the transcriptional factor Spl.

Because the SLPI gene codes for an inhibitor of neutrophil elastase, it is remarkable that the coding exons of the SLPI gene appear to be much more stable than those of the $\alpha 1 \mathrm{AT}$ gene, the gene coding for the major antineutrophil elastase in the lung and elsewhere in the body $(14,15)$. Because of the relative inaccessibility of SLPI at the protein level, it has not been possible to examine the SLPI gene product directly for polymorphisms (the approach by which the $\sim 70 \alpha 1 \mathrm{AT}$ alleles were discovered $[14,15])$. To circumvent this problem, we approached the analysis of the SLPI coding exons by using RNase protection of exon sequences amplified from genomic DNA, an approach that has been successful in identifying coding exon mutations in genes such as $\alpha 1 \mathrm{AT}$ gene (16) and coagulation factor VIII gene (46). Further, the DNA analyzed for SLPI mutations was derived from individuals with a broad range of $\alpha 1 \mathrm{AT}$ mutations, many of which occur in high frequency (14, $15)$. Despite this, no polymorphisms were observed in the major SLPI coding exons. In addition, no polymorphisms were detected in individuals who had obstructive lung disease at an early age, but did not have $\alpha 1 \mathrm{AT}$ deficiency or CF, i.e., hypothetically those who had an increased chance of having an abnormal SLPI gene that might be responsible for their disease.

The SLPI gene also appears to be different from the $\alpha 1 \mathrm{AT}$ gene in regards to its specificity and possible modulation of expression. Whereas SLPI is expressed in a mucosal-specific fashion, the $\alpha 1 \mathrm{AT}$ gene is expressed in humans primarily in hepatocytes, to a lesser extent in mononuclear phagocytes and neutrophils, and possibly in intestinal epithelial cells $(5,15,47$, 48). It is unknown what stimuli, if any, may modulate the SLPI gene expression. However, as it is known that $\alpha$ 1AT gene expression decreases in response to phorbol esters (49), and the 5 flanking region of both the SLPI and $\alpha 1 \mathrm{AT}$ genes have multiple potential AP-1 binding sites which are capable of mediating a specific response to induction by phorbol esters $(50,51)$, it is conceivable that the SLPI gene expression may also be modulated by such stimuli.

\section{Acknowledgments}

We thank Dr. Werner Ebert for making the HS-24 cell line available and Theresa Raymer for excellent assistance in preparing the manuscript.

\section{References}

1. Mooren, H. W. D., J. A. Kramps, C. Franken, C. J. L. M. Meijer, and J. A. Dijkman. 1983. Localisation of a low-molecular-weight bronchial protease inhibitor in the peripheral human lung. Thorax. 38:180-183.

2. Thompson, R. C., and K. Ohlsson. 1986. Isolation, properties, and complete amino acid sequence of human secretory leukocyte protease inhibitor, a potent inhibitor of leukocyte elastase. Proc. Natl. Acad. Sci. USA 83:6692-6696.

3. Franken, C., C. J. L. M. Meijer, and J. H. Dijkman. 1989. Tissue distribution of antileukoprotease and lysozyme in humans. J. Histochem. Cytochem. 37:493-498.
4. Vogelmeier, C., R. C. Hubbard, G. A. Fells, H.-P. Schnebli, R. C. Thompson, H. Fritz, and R. G. Crystal. 1991. Anti-neutrophil elastase defense of the normal human respiratory epithelial surface provided by the secretory leukoprotease inhibitor. J. Clin. Invest. 87:482-488.

5. Hubbard, R. C., and R. G. Crystal. 1991. Antiproteases. In The Lung: Scientific Foundations. R. G. Crystal, J. B. West, F. Barnes, E. R. Weibel, and N S. Cherniack, editors. Raven Press, Inc., New York. 1775-1788.

6. Gauthier, F., U. Fryksmark, K. Ohlsson, and J. G. Bieth. 1982. Kinetics of the inhibition of leukocyte elastase by the bronchial inhibitor. Biochim. Biophys. Acta. 700:178-183.

7. Grütter, M. G., G. Fendrich, R. Huber, and W. Bode. 1988. The $2.5 \dot{A} x$-ray crystal structure of the acid-stable proteinase inhibitor from human mucous secretions analysed in its complex with bovine $\alpha$-chymotrypsin. EMBO (Eur. Mol. Biol. Organ.) J. 7:345-351.

8. Kramps, J. A., C. Franken, and J. H. Dijkman. 1988. Quantity of antileucoprotease relative to $\alpha_{1}$-proteinase inhibitor in peripheral airspaces of the human lung. Clin. Sci. 75:351-353.

9. Fryksmark, U., T. Prellner, H. Tegner, and K. Ohlsson. 1984. Studies on the role of antileukoprotease in respiratory tract diseases. Eur. J. Respir. Dis. 65:201-209.

10. Kramps, J. A., C. Franken, and J. H. Dijkman. 1984. ELISA for quantitative measurement of low-molecular-weight bronchial protease inhibitor in human sputum. Am. Rev. Respir. Dis. 129:959-963.

11. Stetler, G., M. T. Brewer, and R. C. Thompson. 1986. Isolation and sequence of a human gene encoding a potent inhibitor of leukocyte proteases. Nucleic Acids Res. 14:7883-7896.

12. Ohlsson, K., M. Rosengren, G. Stetler, M. Brewer, K. K. Hale, and R. C. Thompson. 1987. Structure, genomic organization, and tissue distribution of human secretory leukocyte-protease inhibitor (SLPI): a potent inhibitor of neutrophil elastase. In Pulmonary Emphysema and Proteolysis. J. C. Taylor and C. Mittman, editors. Academic Press, Inc., New York. 307-324.

13. Eisenberg, S. P., K. K. Hale, P. Heimdal, and R. C. Thompson. 1990. Location of the protease-inhibitory region of secretory leukocyte protease inhibitor. J. Biol. Chem. 265:7976-7981.

14. Crystal, R. G., M. L. Brantly, R. C. Hubbard, D. T. Curiel, D. J. States, and M. D. Holmes. 1989. The alpha $a_{1}$-antitrypsin gene and its mutations: clinical consequences and strategies for therapy. Chest. 95:196-208.

15. Crystal, R. G. 1990. al-Antitrypsin deficiency, emphysema, and liver disease: genetic basis and strategies for therapy. J. Clin. Invest. 85:1343-1352.

16. Abe, T., H. Takahashi, M. D. Holmes, D. T. Curiel, and R. G. Crystal. 1989. Ribonuclease A cleavage combined with the polymerase chain reaction for detection of the $\mathrm{Z}$ mutation of the alpha-1-antitrypsin gene. Am. J. Respir. Cell Mol. Biol. 1:329-334.

17. Saiki, R. K., D. H. Gelfand, S. Stoffel, S. J. Scharf, R. Higuchi, G. T. Horn, K. B. Mullis, and H. A. Erlich. 1988. Primer-directed enzymatic amplification of DNA with a thermostable DNA polymerase. Science (Wash. DC). 239:487-491.

18. Trapnell, B. C., C.-S. Chu, S. Jan de Beur, P. K. Pääkkö, and R. G. Crystal. 1990. Differential expression of the cystic fibrosis gene in the human respiratory tract. Clin. Res. 38:444a. (Abstr.)

19. Chomczynski, P., and N. Sacchi. 1987. Single-step method of RNA isolation by acid guanidinium thiocyanate-phenol-chloroform extraction. Anal. Biochem. 162:156-159.

20. Gunning, P., P. Ponte, H. Okayama, J. Engel, H. Blau, and L. Kedes. 1983. Isolation and characterization of full-length cDNA clones for human $\alpha-, \beta-$, and $\boldsymbol{\gamma}$-actin mRNAs: skeletal but not cytoplasmic actins have an amino-terminal cysteine that is subsequently removed. Mol. Cell. Biol. 3:787-795.

21. Appelhans, B., B. Ender, G. Sachse, T. Nikiforov, H. Appelhans, and W. Ebert. 1987. Secretion of antileucoprotease from a human lung tumor cell line. FEBS (Fed. Eur. Biochem. Soc.) Lett. 224:14-18.

22. Takahashi, H., T. Nukiwa, P. Basset, and R. G. Crystal. 1988. Myelomonocytic cell lineage expression of the neutrophil elastase gene. J. Biol. Chem. 263:2543-2547.

23. Groudine, M., M. Peretz, and H. Weintraub. 1981. Transcriptional regulation of hemoglobin switching in chicken embryos. Mol. Cell. Biol. 1:281-288.

24. Nevins, J. R. 1987. Isolation and analysis of nuclear RNA. Methods Enzymol. 152:234-241.

25. Weintraub, H., and M. Groudine. 1976. Chromosomal subunits in active genes have an altered conformation. Science (Wash. DC). 193:848-856.

26. Sanger, F., S. Nicklen, and A. R. Coulson. 1977. DNA sequencing with chain-terminating inhibitors. Proc. Natl. Acad. Sci. USA. 74:5463-5467.

27. Calzone, F. J., R. J. Britten, and E. H. Davidson. 1987. Mapping of gene transcripts by nuclease protection assays and cDNA primer extension. Methods Enzymol. 152:611-632.

28. Pearson, W. R., and D. J. Lipman. 1988. Improved tools for biological sequence comparison. Proc. Natl. Acad Sci. USA 85:2444-2448.

29. Lee, W., A. Haslinger, M. Karin, and R. Tjian. 1987. Activation of transcription by two factors that bind promoter and enhancer sequences of the human metallothionein gene and SV40. Nature (Lond.). 325:368-372. 
30. Mitchell, P. J., C. Wang and R. Tjian. 1987. Positive and negative regulation of transcription in vitro: enhancer-binding protein AP- 2 is inhibited by SV 40 $\mathrm{T}$ antigen. Cell. 50:847-861.

31. Gidoni, D., W. S. Dynan, and R. Tjian. 1984. Multiple specific contacts between a mammalian transcription factor and its cognate promoters. Nature (Lond.). 312:409-413.

32. Johnson, P. F., W. H. Landschulz, B. J. Graves, and S. L. McKnight. 1987. Identification of a rat liver nuclear protein that binds to the enhancer core element of three animal viruses. Genes Dev. 1:133-146.

33. Beato, M. 1989. Gene regulation by steroid hormones. Cell. 56:335-344.

34. Montminy, M. R., and L. M. Bilezikjian. 1987. Binding of a nuclear protein to the cyclic-AMP response element of the somatostatin gene. Nature (Lond.). 328:175-178.

35. Ko, H.-S., P. Fast, W. McBride, and L. M. Staudt. 1988. A human protein specific for the immunoglobulin octamer DNA motif contains a functional homeobox domain. Cell. 55:135-144.

36. Mitchell, P. J., and R. Tjian. 1989. Transcriptional regulation in mammalian cells by sequence-specific DNA binding proteins. Science (Wash. DC). 245:371-378.

37. Houck, C. M., F. P. Rinehart, and C. W. Schmid. 1979. A ubiquitous family of repeated DNA sequences in the human genome. J. Mol. Biol. 132:289306.

38. Deininger, P. L., D. J. Jolly, C. M. Rubin, T. Friedmann, and C. W. Schmid. 1981. Base sequence studies of 300 nucleotide renatured repeated human DNA clones. J. Mol. Biol. 151:17-33.

39. Yoshimura, K., H. Nakamura, B. C. Trapnell, W. Dalemans, A. Pavirani, J.-P. Lecocq, and R. G. Crystal. 1991. The cystic fibrosis gene has a "housekeeping"-type promoter and is expressed at the low levels in cells of epithelial origin. $J$. Biol. Chem. 266:9140-9144.

40. Seemüller, U., M. Arnhold, H. Fritz, K. Wiedenmann, W. Machleidt, R. Heinzel, H. Appelhans, H.-G. Gassen, and F. Lottspeich. 1986. The acid-stable proteinase inhibitor of human mucous secretions (HUSI-I, antileukoprotease): complete amino acid sequence as revealed by protein and cDNA sequencing and structural homology to whey proteins and Red Sea turtle proteinase inhibitor. FEBS (Fed. Eur. Biochem. Soc.) Lett. 199:43-48.
41. De Water, R., L. N. A. Willems, G. N. P. Van Muijen, C. Franken, J. A. M. Fransen, J. H. Dijkman, and J. A. Kramps. 1986. Ultrastructural localization of bronchial antileukoprotease in central and peripheral human airways by a gold-labeling technique using monoclonal antibodies. Am. Rev. Resp. Dis. 133:882-890.

42. Shaw, G., and R. Kamen. 1986. A conserved AU sequence from the $3^{\prime}$ untranslated region of GM-CSF mRNA mediates selective mRNA degradation. Cell. 46:659-667.

43. Wilson, T., and R. Treisman. 1988. Removal of poly(A) and consequent degradation of c-fos mRNA facilitated by $3^{\prime}$ AU-rich sequences. Nature (Lond.). 336:396-399.

44. Dynan, W. S. 1986. Promoters for housekeeping genes. Trends Genet. 2:196-197.

45. Maniatis, T., S. Goodbourn, and J. A. Fischer. 1987. Regulation of inducible and tissue-specific gene expression. Science (Wash. DC). 236:1237-1245.

46. Levinson, B., R. Janco, J. Phillips III, and J. Gitschier. 1987. A novel missense mutation in the factor VIII gene identified by analysis of amplified hemophilia DNA sequences. Nucleic Acids Res. 15:9797-9805.

47. Mornex, J.-F., A. Chytil-Weir, Y. Martinet, M. Courtney, J.-P. Lecocq, and R. G. Crystal. 1986. Expression of the alpha-1-antitrypsin gene in mononuclear phagocytes of normal and alpha-1-antitrypsin-deficient individuals. J. Clin. Invest. 77:1952-1961.

48. Perlmutter, D. H., J. D. Daniels, H. S. Auerbach, K. De Schryver-Kecskemeti, H. S. Winter, and D. H. Alpers. 1989. The $\alpha_{1}$-antitrypsin gene is expressed in a human intestinal epithelial cell line. J. Biol. Chem. 264:9485-9490.

49. Trapnell, B. C., I. Nagaoka, A. Chytil, and R. G. Crystal. 1989. Surface activation-induced upregulation of $\alpha 1$-antitrypsin gene expression in mononuclear phagocytes is associated with selective $5^{\prime}$ non-coding exon usage. Clin. Res. 37:482a. (Abstr.)

50. Angel, P., M. Imagawa, R. Chiu, B. Stein, R. J. Imbra, H. J. Rahmsdorf, C. Jonat, P. Herrlich, and M. Karin. 1987. Phorbol ester-inducible genes contain a common cis element recognized by a TPA-modulated trans-acting factor. Cell. 49:729-739.

51. Lee, W., P. Mitchell, and R. Tjian. 1987. Purified transcription factor AP-1 interacts with TPA-inducible enhancer elements. Cell. 49:741-752. 